Sādhanā Vol. 39, Part 6, December 2014, pp. 1563-1572. (C) Indian Academy of Sciences

\title{
Exploring the electrodes alignment and mushrooming effects on weld geometry of dissimilar steels during the spot welding process
}

\author{
NACHIMANI CHARDE \\ ${ }^{1}$ Department of Mechanical, Material and Manufacturing Engineering, \\ The University of Nottingham Malaysia Campus, Jalan Broga, \\ 43500 Semenyih, Selangor Darul Ehsan, Malaysia \\ ${ }^{2}$ Department of Mechanical Engineering, Faculty of Engineering, University of \\ Malaya, 50603 Kuala Lumpur, Malaysia \\ e-mail: nachi.charde@nottingham.edu.my;nachimani@um.edu.my
}

MS received 18 March 2013; revised 12 June 2014; accepted 7 August 2014

\begin{abstract}
The class two of RWMA electrode caps has very common applicationpurpose for the welding of steels and withstand for high thermal application on wrought cast. It has been experimentally used to weld carbon and stainless steels up to 900 weld attempts using AC waveform, C-type JPC $75 \mathrm{kVA}$, Japanese made spot welder. So the electrode alignments and resulting mushrooming effects are finally analysed in this research as well as the weld geometry of dissimilar (carbon and stainless) steels. When considering such weld joints, the heat imbalances are very interesting factors on spot welding research and therefore I have simulated the dissimilar weld joints using Ansys 14. Initially, it was simulated and later those results are compared with real welded samples. The common welded regions such as: fusion zones, heat affected zones, heat extended zones and base metals are all well-noticed for carbon steel sides but not for stainless steel sides. Besides, the electrode mushrooming effect on both sides of electrodes are not parallel deterioration and it has some demerits on internal structure indeed. Some of the dissimilar welded samples and electrode caps are eventually underwent metallurgical test to identify the improper alignment.
\end{abstract}

Keywords. Spot welding; dissimilar joints; electrode deformation; electrode mushrooming.

\section{Introduction}

The geometry of dissimilar weld joints is basically made of asymmetrical weld nuggets. In such welding joints, the heat imbalances will be the main factor and it has to be properly aligned in the middle of base metal to produce a proper weld nugget (Aravinthan \& Nachimani 2011a). So the electrode alignment during welding process plays a significant role on the formation of weld 
geometry. In this research, the carbon and stainless steels are analysed for the weld nuggets alignment as well as the mushrooming growth of electrodes after 900 welds were done. The growth of the weld nugget is therefore determined by the welding current, sufficient time for current delivery, reasonable electrode pressing force and sufficient area for current delivery (electrode tip) (Aravinthan \& Nachimani 2011b). Basically, the welding current and weld time lead to the root generation of heat in the welding process while the electrode pressing force and electrode tips' accomplish it successfully (Mehdi et al 2008). Although the welding current and weld time cause the heat generation at the concerned areas (electrode tips' area); the electrode tips diameter and electrode pressing forces are also directly influencing the welding process (Nachimani 2012). So the class two electrode types are engaged in the welding process and consequently monitored the deformation and mushrooming effects after approximately 900 welds were done.

\section{Experimentation}

The carbon and stainless steels were prepared in rectangular shape (Chang et al 2006) with a size of the length $(200 \mathrm{~mm})$; width $(25 \mathrm{~mm})$ and thickness $(1 \mathrm{~mm})$. A pair of water cooled (2 litters per minutes) 30 degree truncated type of electrodes ( $5 \mathrm{~mm}$ of diameter) was used to join (JPC 75 $\mathrm{kVA}$ ) of these base metals as shown in figure 1 . The pair of test sample was initially loaded on the top of lower electrode (tip) of the welder as overlaying $60 \mathrm{~mm}$ on each other (lap joint) and then the initiating pedal was pressed. The upper electrode lever has moved towards the lower electrode and squeezed the based metals that placed in between (Rao et al 2009). The welding current was released immediately after the squeezing cycles of pneumatic based electrode actuation is achieved. Thereafter the electrode pressing mechanism has consumed some time for cold work and eventually returned to the home position of upper electrode (Yeung \& Thornton 1999). These process controlling parameters (welding current, weld time and electrode pressing force)

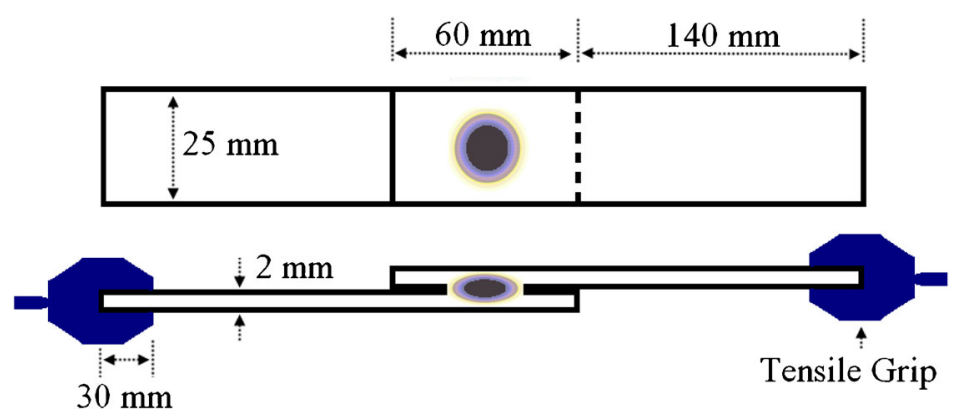

Figure 1. Lap joint welding process.

Table 1. The chemical properties of base metals.

\begin{tabular}{lccccccc}
\hline 304L (2B) & Austenitic stainless steel & & & & & \\
Element & $\mathrm{C}$ & $\mathrm{Cr}$ & $\mathrm{Ni}$ & $\mathrm{Mn}$ & $\mathrm{Si}$ & $\mathrm{S}$ & $\mathrm{P}$ \\
& 0.048 & 18.12 & 8.11 & 1.166 & 0.501 & 0.006 & 0.030 \\
& & & & & & & \\
Carbon steel & & & $\mathrm{Ni}$ & $\mathrm{Mn}$ & $\mathrm{Si}$ & $\mathrm{S}$ & $\mathrm{P}$ \\
Element & $\mathrm{C}$ & $\mathrm{Cr}$ & $\mathrm{Ni}$ & 0.90 & 0.006 & 0.050 & 0.040 \\
& 0.23 & & & & & & \\
\hline
\end{tabular}


Table 2. General properties of CMW copper based alloys.

\begin{tabular}{ll}
\hline CMW Alloy (Class 2) & CMW 3 (ME 14 Z) \\
\hline Condition & Cast wrought \\
Principle elements & Copper, chromium \\
RWMA alloy number & 2.18200 \\
Rockwell hardness (HRB) & $70-83 \mathrm{~B}$ \\
Electrical conductivity \% IACS & $80-85$ \\
Ultimate tensile strength (PSI) & $55-75 \mathrm{k}$ \\
Elongation \% in 2" & $15-20$ \\
Permanent softening begin at & $500^{\circ} \mathrm{C}$ \\
\hline
\end{tabular}

Figure 2. Hot press mounted samples for SEM scanning.

were set before the welding process starts; based on the manufacturers of welding lobe for $1 \mathrm{~mm}$ thicknesses. Table 1 lists the chemical properties of base metals and table 2 lists the general description of copper based alloy-electrodes that used in this analysis.

The welded sample was cut at the line of its diameter and mounted using resin powder on hot press mount (Marashi et al 2008). The mounted samples (figure 2) were roughly polished using silicon papers 1200/800 p and 600/200 p; and also continuously polished using Metadi polishing cloth with suspension liquid of 0.05 micron. This polishing process has been conducted about thirty minutes to one hour on each sample until the shining surface was seen. At last, the ferric chloride $(500 \mathrm{ml})$ was used to immerse these well-prepared (shining surface) samples in a pot about 30-45 minutes. After that the samples were rinsed off using plain water; dried using air blower; anti-corrosion liquid was applied and kept in vacuum chamber for SEM scanning. Similar procedures were carried out to analyse the macro and micro structural changes of electrodes after about 900 welds were made in one year.

\section{Results and discussion}

\subsection{A comparative study of simulation and real type of dissimilar weld joint}

A simulation of dissimilar (carbon and stainless steel) weld joint was carried out prior to the real experiment using Ansys 14 (figure 3). The simulation results have revealed asymmetrical fusion zones due to dissimilar thermal charecteristics for dissimilar weld joint. So in overall, I have categorized those regions as (i) fusion zone, (ii) heat affected zone, (iii) heat extended zone and (iv) base metal. So it is obvious that the heat imbalances were noticed due to different electrical properties of base metals.

Table 3 lists the general properties of carbon and stainless steels. From table 1, it is clearly seen that the melting point of both metals vary from each other so the melting process starts 


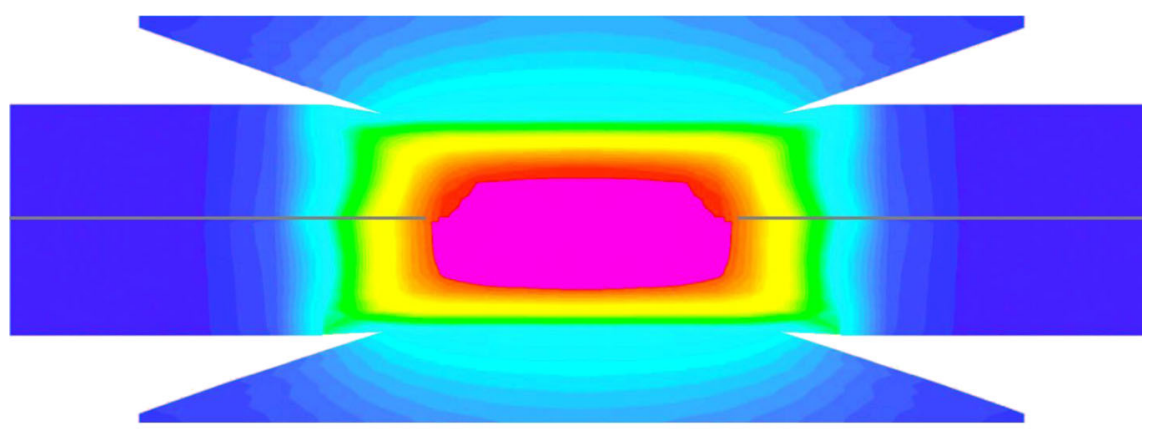

Temperature $\left({ }^{\circ} \mathrm{C}\right)$

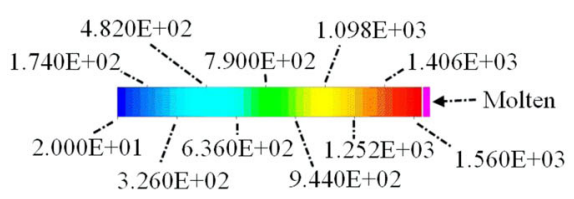

Fusion Zone (FZ)

Heat Affected Zone (HAZ)

Heat Extended Zone (HEZ)

Base Metal (BM)

Figure 3. Simulating a dissimilar weld joint (before solidification starts).

Table 3. General properties of base metals.

\begin{tabular}{lll}
\hline Properties & \multicolumn{1}{c}{ Stainless steel } & \multicolumn{1}{c}{ Carbon steel } \\
\hline Density & $8.00 \mathrm{~g} / \mathrm{cm}^{3}$ & $7.85 \mathrm{~g} / \mathrm{cm}^{3}$ \\
Melting point & $1400-1450^{\circ} \mathrm{C}$ & $1426-1538^{\circ} \mathrm{C}$ \\
Electrical resistivity & $6.89 \times 10^{-7} \Omega . \mathrm{m}$ & $1.611 \times 10^{-7} \Omega . \mathrm{m}$ \\
Thermal conductivity & $16.2 \mathrm{~W} / \mathrm{m} . \mathrm{K}(\mathrm{min})$ & $54 \mathrm{~W} / \mathrm{m} . \mathrm{K}(\mathrm{min})$ \\
Thermal expansion & $17.2 \times 10^{-6} / \mathrm{K}$ & $12 \times 10^{-6} / \mathrm{K}$ \\
\hline
\end{tabular}

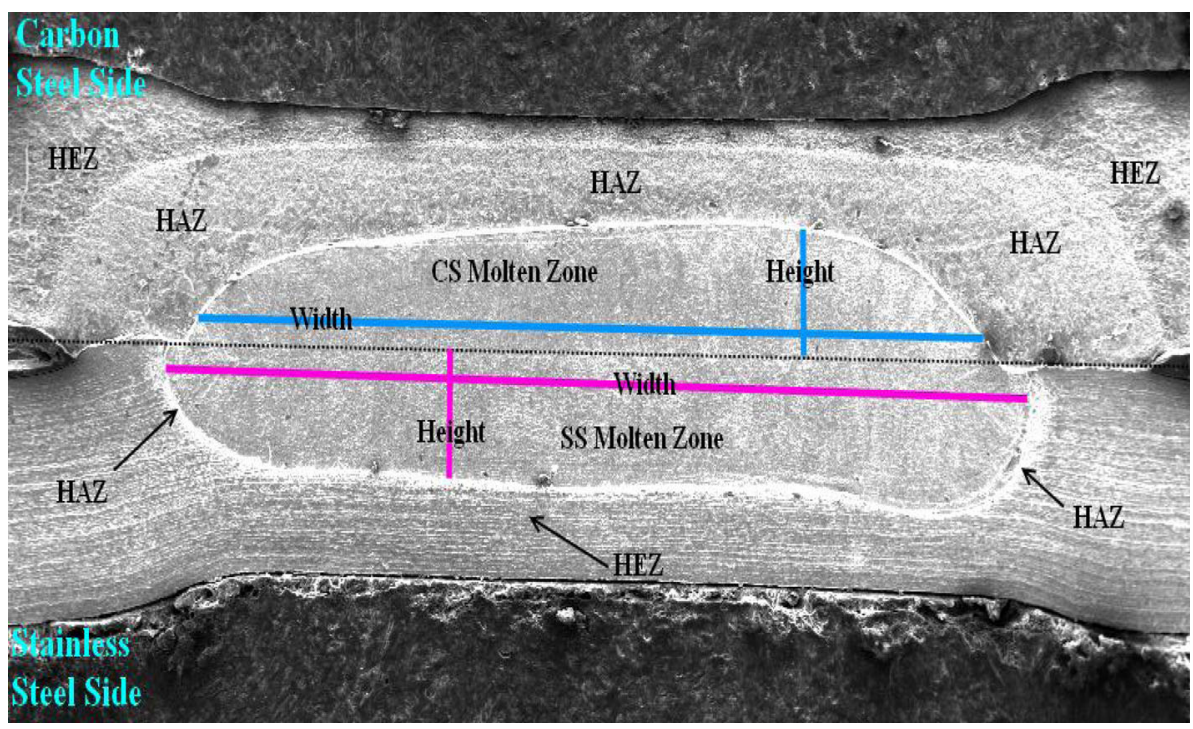

Figure 4. A real macro view of dissimilar weld joint (after solidification). 


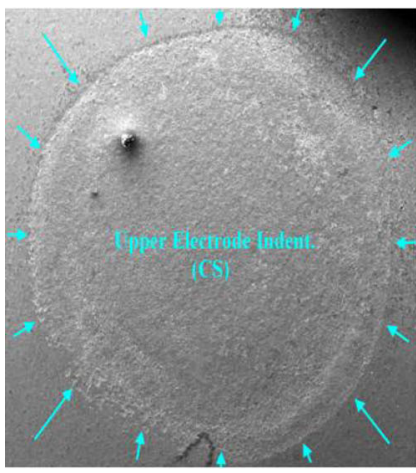

(a) Upper view

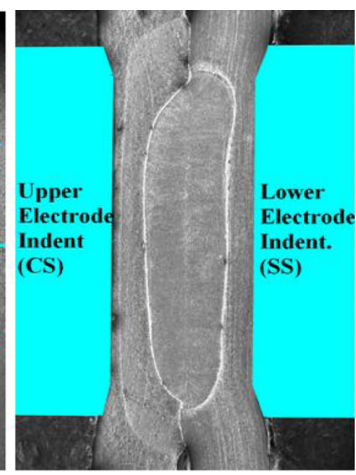

(b) Cross section

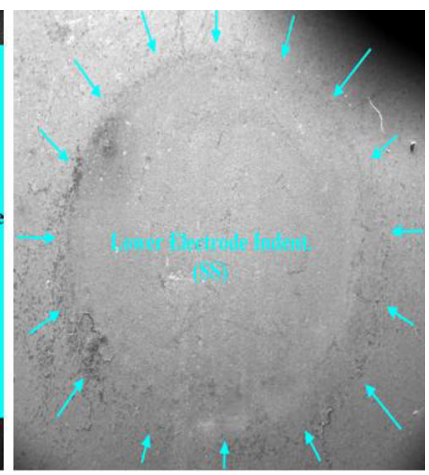

(c) Lower view

Figure 5. A real macro view of dissimilar weld joint (best).

at different circumtances (Jamasri et al 2011). Thus, the thermal conductivity coefficients are higher in carbon steels as compared to stainless steels; therefore wider ranges of heat affected and heat extended zones (HAZ and HEZ) are visible at the carbon steel side. However, the thermal expansion coefficient is lower as compare to stainless steel; so that the melting rate differs and resulting smaller width and also shorter height of fusion zone. On the other side, the stainless steels seemed to have higher thermal expansion coefficient but lower thermal conductivity coefficient. So the heat affected zones (HAZ) was smaller in region but the fusion zone was wider and higher as compared to carbon steel (Dursun \& Zyurek 2008). Technically, this phenomenon is called as heat imbalance. A real dissimilar weld joint of carbon and stainless steel is shown in figure 4 . Some of the regions that revealed by the simulated results were exactly seen at the stainless steels (Shamsul \& Hisyam 2007). Moreover, the heat extended regions of stainless steels are not certainly seen with the macrograph image clearly, but it did exist (Fukumoto et al 2008). This is because of the nature of stainless steel as it does not easily create different grain sizes to differentiate the heat affected and heat extended regions. Unlike carbon steel, as it shows all the regions with different grain sizes and therefore easily identifiable.

\subsection{Electrode alignment during welding process}

The welded zones were analysed for the electrodes alignment and found to be very few good weld using pneumatic based electrode actuation system. One of them is presented in figure 5 . The upper and lower electrodes' surfaces were properly placed during welding process so that a balanced weld nugget was obtained. The welded zone has asymmetrical fusion zone (FZ), asymmetrical heat affected zone (HAZ), asymmetrical heat extended zone (HAZ) and symmetrical supporting base metals (BM) (Cha \& Na 2003). There was no side effect on the weld surfaces because the electrodes were very new at the time of welding except small pores (Martín et al 2009). The pores were noticed due to unstable forging force during welding process and it could not be fully elliminated in pneumatic based electrode actuation system of JPC $75 \mathrm{kVA}$ spot welder.

Figure 6 shows the vertical mismatch during welding process. The upper and lower electrodes are vertically misaligned so that a portion of weld nugget was uncontrollably developed at the right hand side (point $\mathrm{A}$ ). This portion can easily cause heavy expulsion if the heating process goes little longer. Moreover, the upper side base metal (carbon steel) had little corossion and 


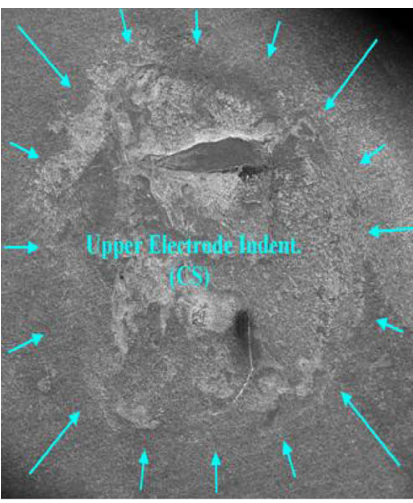

(a) Upper view

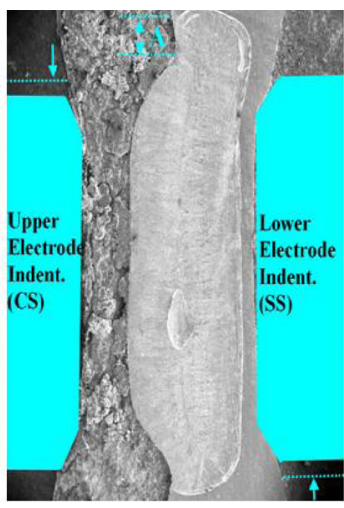

(b) Cross section

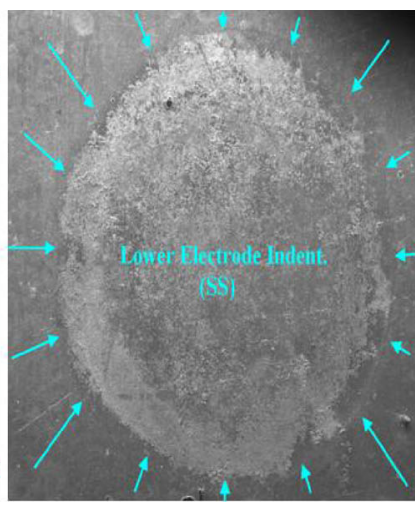

(c) Lower view

Figure 6. A real macro view of dissimilar weld joint (vertically mis-aligned).

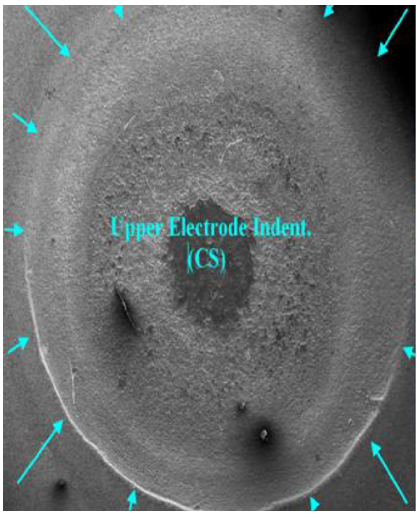

(a) Upper view

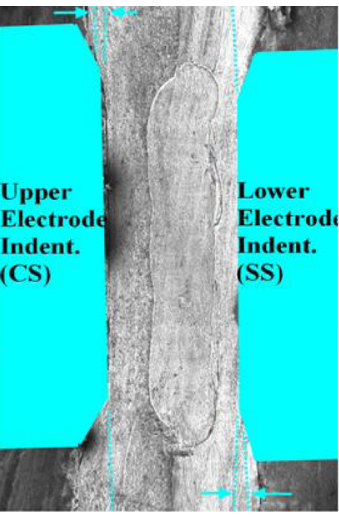

(b) Cross section

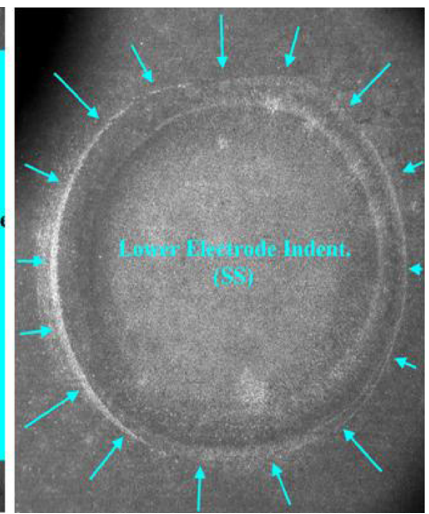

(c) Lower view

Figure 7. A real macro view of dissimilar weld joint (horizontally mis-aligned).

it was not even fully eliminated during welding process. So the upper indentation is partially damaged and cause odd-surface outlook on the carbon steel side.

Meanwhile, the horizontal mismatch of electrode had caused odd type of weld diameter as shown in figure 7. However, the upper and lower indentation is not very much affected except inclusions (Yuhang et al 2011). Some inclusions were seen at the carbon steel side. This kind of misalignment leads to electrode mushrooming growth and increases the diameter of electode tips predominantly.

\subsection{Electrode mushrooming effect}

The class two spot welding electrodes are made up of copper and chromium elements, according to the RWMA classification (Bower et al 1990). It has two phase mixture of chromium and 

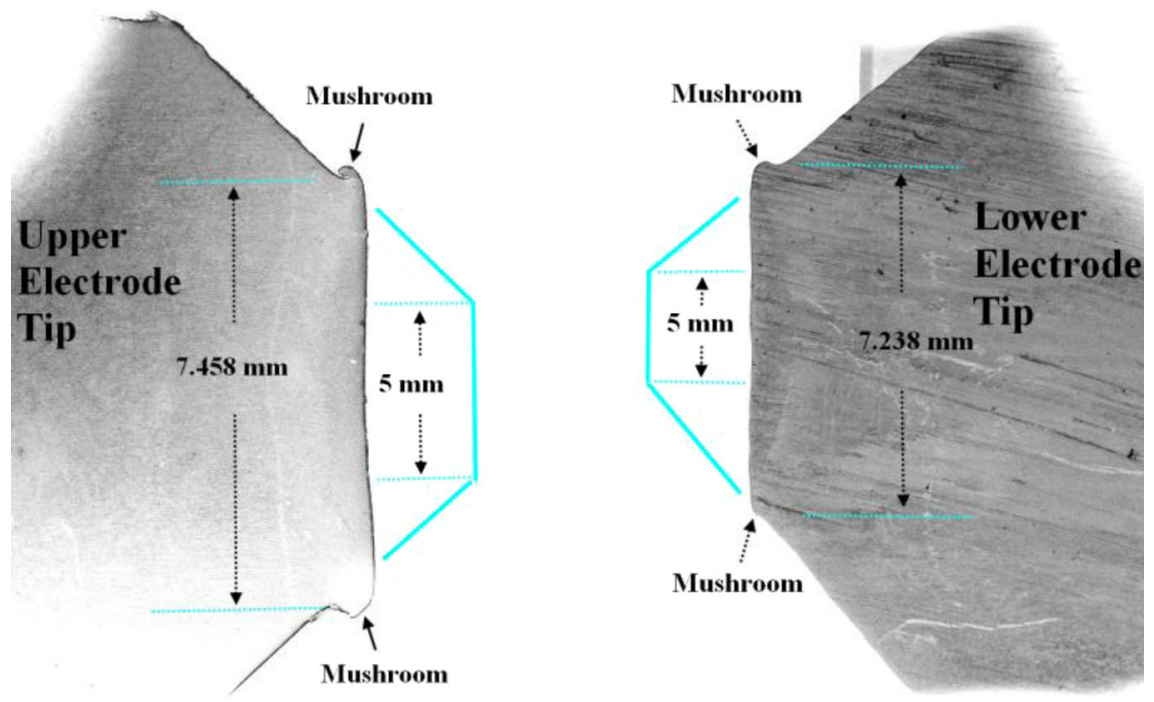

Figure 8. A macrograph view of electrodes after 900 welding process Source: (Welding and Cutting).

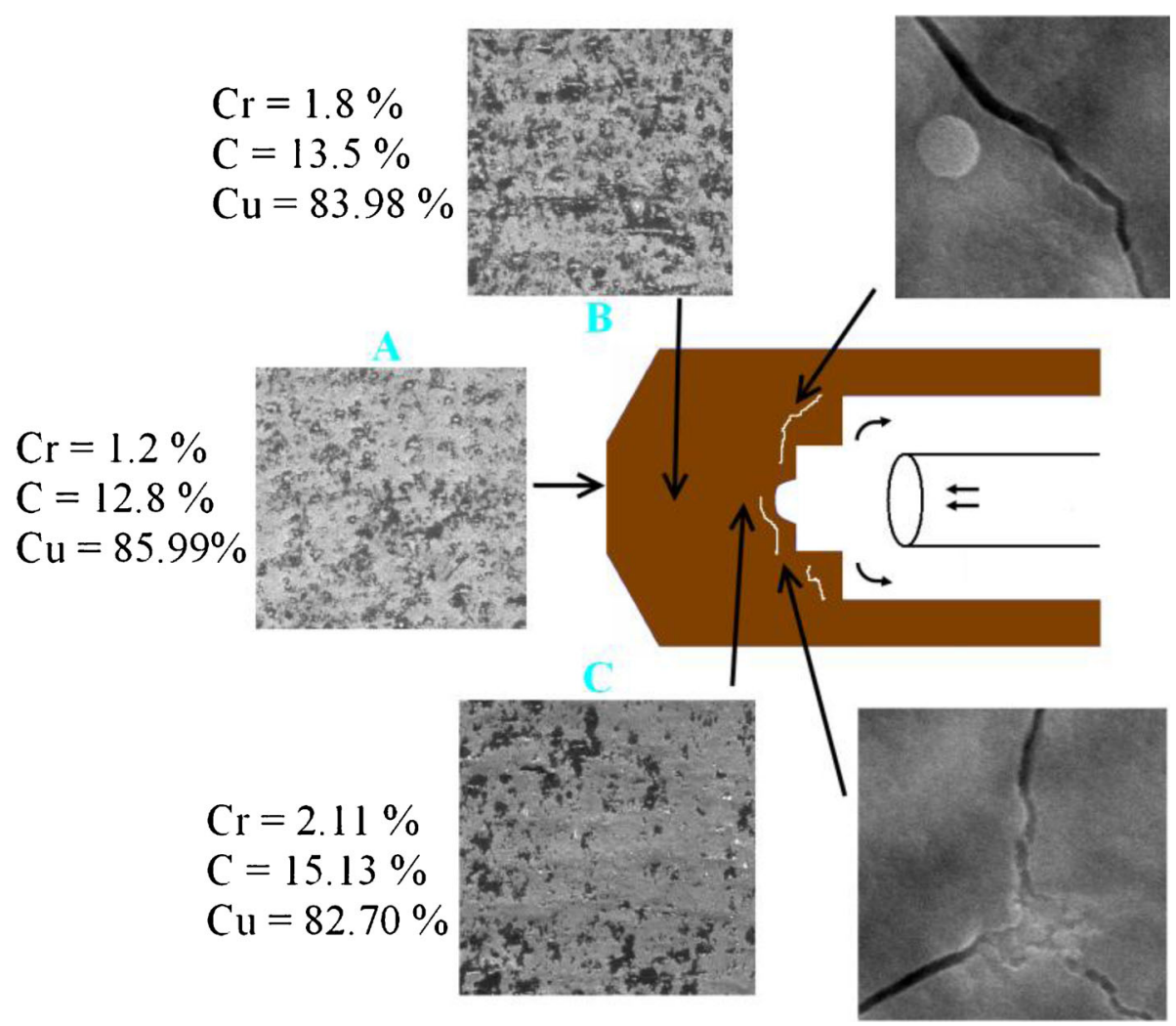

Figure 9. The electrode microstructural view Source: (Welding and Cutting). 
alpha copper. Basically, the changes in properties can happen at the rise of temperature due to the precipitation of chromium out of the solid solution. This is what has been widely noticed in the micro structural view of electrodes. As the numbers of welds are repeatedly welded on carbon and stainless steels, the mushrooming effect are growing due to heat exposure at the electrode tips' areas. In this research, the original electrode tip of both sides was $5 \mathrm{~mm}$ of diameter and it was mushroomed to $7.458 \mathrm{~mm}$ on upper electrode tip side and $7.238 \mathrm{~mm}$ on lower electrode tip side. Figure 8 shows the macrograph of electrode tips which was used to weld about 900 times.

Having considered the mechanical and chemical changes that took place on the electrodes after 900 numbers of welds; it was SEM-scanned for structural changes (figure 9). Point A of figure 9 was the electrode tip at which the base metals' molten heat $\left(\approx 1600^{\circ} \mathrm{C}\right)$ was directly exposed. The point $\mathrm{B}$ and $\mathrm{C}$ are the places lead to the electrode holder which are also exposed to the thermal expansions. Thus, the chromium to copper ratio is affected due to heat exposure as shown in figure 9. The micro structural views shows that the chromium precipitation is higher at the tip (point A) due to the direct exposure of heat beyond melting points of steels (Chen et al 2005). The point B has balanced chromium to copper ratio between point $A$ and $C$. However, the different cooling rate at point $\mathrm{C}$ due to water coolant (2 litters per minutes) inside the electrodes prevents chromium precipitation but resulted cracks on upper electrode side after 900 welds (figure 9).

Eventually, the electrode tip diameter was measured for every hundred weld attempts and it was shown in figure 10. The upper electrode's mushrooming effect was slightly higher than the lower electrode because it enacts for the pressing forces (impact) everytime during the welding process.

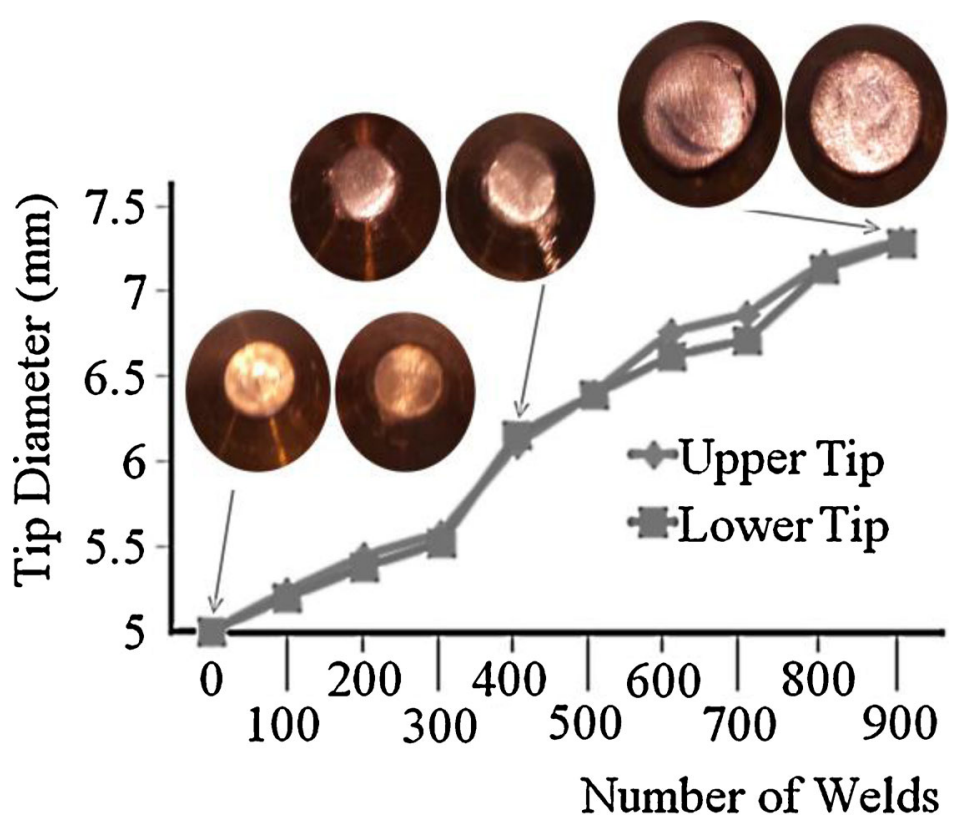

Figure 10. The electrode microstructural changes Source: (Welding and Cutting). 


\section{Conclusion}

This paper dealt with the weld zone geometry using carbon and stainless steels for the electrode alignment and its mushrooming effects. The following conclusions were drawn.

(i) A simulation of spot welding process showed that the heat imbalances occurred during the welding of carbon and stainless steels.

(ii) A proper weld zone had asymmetrical weld nugget consisted of fusion, heat affected, heat extended and base metal zones.

(iii) The proper electrodes' alignment played an important role on quality of the proper weld geometry regardless of thicknesses.

(iv) Misalignment of electrodes caused expulsion and also lead to poor weld zones.

(v) Electrodes class two (chromium and copper) showed cracks on its internal structure after 900 weld attempts using carbon and stainless steel.

(vi) The precipitation of chromium out of the solid solution was noticed at the tip of electrodes which caused mushrooming effects after significant number of weld trials.

(vii) The initial weld processes up to 400 times increased the electrode tip (mushroom) diameter to about $23 \%$ on upper electrode and $19 \%$ on lower electrode.

(viii) The further weld processes up to 900 times have increased the electrode tip diameter to about $49 \%$ on upper electrode and $45 \%$ of lower electrode.

\section{Acknowledgements}

Author would like to thank the Ministry of Science, Technology and Innovation of Malaysia (MOSTI) for financial support. This research outcome is a part of Mr Nachimani's PhD research work.

\section{References}

Aravinthan A and Nachimani C 2011a Analysis of spot weld growth on mild and stainless steel. Welding Journal 143-147

Aravinthan A and Nachimani C 2011b Metallurgical study of spot welds growth on mild steel with $1 \mathrm{~mm}$ and $2 \mathrm{~mm}$ thicknesses. Journal - The Institution of Engineers Malaysia 72: 36-42

Bower R J, Sorensen C D and Eager T W 1990 Electrode geometry in resistance spot welding. Welding Journal 45-51

Cha B W and Na S J 2003 A study on the relationship between welding conditions and residual stress of resistance spot welded 304-type stainless steels. J. Manufactur. Syst. 22(31)

Chang B H et al 2006 Effect of forging force on fatigue behavior of spot welded joints of aluminum alloy 5182. J. Manufactur. Sci. Eng. 4: 345-352

Chen Z, Zhou Y and Scotchmer N 2005 Coatings on resistance welding electrodes to extend life. SAE International $1-4$

Dursun O and Zyurek 2008 An effect of weld current and weld atmosphere on the resistance spot weld ability of 3041 austenitic stainless steel. Mater. Design 29: 597-603

Fukumoto Shinji, Kana Fujiwara, Shin Toji and Atsushi Yamamoto 2008 Small Scale Resistance Spot Welding of Austenitic Stainless Steels. Mater. Sci. Eng. A 492: 243-249

Jamasri M N, Ilman R, Soekrisno and Triyono 2011 Corrosion fatigue behaviour of RSW dissimilar metal welds between carbon steel and austenitic stainless steel with different thickness. Procedia Engineering 10: 649-654 
Marashi P, Pouranvari M, Amirabdollahian S, Abedi A and Goodarzi M 2008 Microstructure and failure behavior of dissimilar resistance spot welds between low carbon galvanized and austenitic stainless steels. Mater. Sci. Eng. A 175-180

Martín Óscar, Pilar De Tiedra, Manuel López, Manuel San-Juan, Cristina García, Fernando Martín and Yolanda Blanco 2009 Quality prediction of resistance spot welding joints of 304 austenitic stainless steel. Materials and Design 68-77

Mehdi M H, Abadi A and Pouranvari M 2008 Correlation between macro/micro structure and mechanical properties of dissimilar rsw of AISI 304 austenitic stainless steel and AISI 1008 low carbon steel. Scientific paper of Association of Metallurgical Engineers of Serbia 2: 56-63

Nachimani C 2012 Spot weld growth on medium carbon steel (Part 1). Int. J. Mech. Mater. Eng. 7(1): 36-40

Rao Z H, Liao S M, Tsai H L, Wang P C and Stevenson R 2009 Mathematical modeling of electrode cooling in resistance spot welding. Welding Journal 111-119

Shamsul J B and Hisyam M M 2007 Study of spot welding of austenitic stainless steel type 304. J. Appl. Sci. Res. 3(11): 1494-1499

Yeung K S and Thornton P H 1999 Transient thermal analysis of spot welding electrodes. Welding Journal $1-6$

Yuhang Yang, Xilong Qu, Yiping Luo and Aimin Yang 2011 Effect of resistance spot welding parameters on the austenitic stainless steel 304 grade by using 23 factorial designs. Adv. Mater. Res. 216: 666-670 